\title{
Research on Performance Evaluation of University Scientific Research Project
}

\author{
Yun Ling \\ Financial Department, Jiangsu University of Science and Technology, Zhenjiang 212003, China.
}

\begin{abstract}
The performance evaluation of university scientific research projects is an important link of the funds management of university scientific research projects, which is the basis for improving utilization benefit of scientific research funds, the key link for rational allocation of scientific research funds, and the important prerequisite for arousing scientific research personnel' enthusiasm. At present, there are primal problems in the performance evaluation of university scientific research projects, for example, insufficient understanding of importance, system deficiency, lack of index system, simple evaluation methods and so on. Correspondingly, the countermeasures adopted mainly include deepening the understanding, establishing rules and regulations, setting index, improving methods and so on.
\end{abstract}

Keywords: University scientific research project, performance evaluation of university scientific research project, problem and countermeasure.

\section{Introduction}

The performance evaluation of university scientific research projects is to conduct scientific, objective and fair measurement comparison and comprehensive evaluation for research process, funds expenditure and research results of university scientific research projects by using certain evaluation indexes, reasonable evaluation criteria, and scientific evaluation methods, thus evaluating the efficiency relationship between the investment and outcome of this research project. Although some experts have proposed to carry out performance evaluation of university research projects in China, it is known that these viewpoints are still in the proposal stage, and there is no special and specific research result. At the same time, although many experts have proposed that performance evaluation has a very important role and significance for the management and acceptance check of university scientific research projects, no one has fully discussed it. This paper puts forward primal problems in the performance evaluation of university scientific research projects, and specifically proposes improvement measures and countermeasures.

\section{Existing Problems in the Performance Evaluation of University Scientific Research Projects}

It can be found from research conditions in recent years that the performance evaluation of university scientific research projects is still an emerging field, whether theoretical research or practice, it is still only in the exploration stage. Therefore, there are many problems in the performance evaluation of university scientific research projects; of course, there are two reasons for the existence of these problems, the first is not ready in theory and thought, the second is lack of system, which lead to lack of evaluation system and the improper evaluation method. In order to improve and popularize the performance evaluation of university scientific research projects, it is necessary to solve from these two aspects, thus constructing theoretical system, institutional system, evaluation system and method system for the perfect, scientific and reasonable performance evaluation of university scientific research projects.

First, the importance understanding of performance evaluation of university scientific research projects is insufficient. Whether the scientific research management department, financial management department or project leader in universities, there are deficiencies in understanding this problem. The scientific research management departments in universities only pay attention to "twohead management" in scientific research management, namely, emphasize the management of declaration work and report, and the evaluation and management of scientific research performance 
are often neglected in this management. At present, the financial department of universities only manages the compliance of funds use; there are lacks of corresponding management and evaluation for the economics, efficiency and effectiveness of funds use. The project leaders do not recognize the importance of performance evaluation, some leaders even think that scientific research funds is their own private funds, can spend it at will, and not even consider the performance problems of funds use and expenditure. What is more, some experts think that the "scientific research performance" index should not be established in the performance management in universities; the reason is that scientific research is not the result of the school's input or output in the past or recent years, but a long-term accumulative process. True, scientific research performance cannot be evaluated in accordance with business funds, but the use of scientific research funds can still be carry out performance evaluation, which can be implemented at least within a reasonable scientific research cycle.

Second, the system of performance evaluation of university scientific research projects is deficient. Today, the financial performance evaluation system in universities is still not perfect, and the system of performance evaluation of scientific research projects in universities is in deficient state. Apparently, in order to implement the performance evaluation of scientific research projects in universities, there must be corresponding systems to guarantee, but so far, national or provincial unified laws and regulations on the performance evaluation of scientific research projects in universities have not been published, let alone the corresponding methods, organizations, coordinative measures, report systems, evaluation results monitoring systems and so on. This deficiency of system makes the performance evaluation work of scientific research projects in universities difficult, and there is no clear development direction and scientific evaluation system.

Third, the index system of performance evaluation of university scientific research projects is insufficient. The performance evaluation of university scientific research projects is a complex system, and there must be corresponding complete scientific evaluation index, however, this index system has not yet been established. First, the current index system cannot reasonably reflect the performance of university scientific research; second, the evaluation index are not systematic, and cannot achieve the correlation and emphasis of different performance; third, cannot reflect the existence of nonfinancial performance, evaluation of scientific research performance should consider not only financial performance, but also non-financial performance, namely the social benefits of scientific research results.

Fourth, the method of performance evaluation of university scientific research projects is simple and cannot realize the function of evaluation. At present, the methods of performance evaluation of university scientific research projects mainly focus on compliance evaluation, and there are basically no methods for evaluating their benefits. Moreover, these methods are too flat and singular, and cannot conduct comprehensive, stereoscopic and scientific evaluation from different levels, different project natures and levels. At the same time, because the performance evaluation of university scientific research is mostly placed in the system of financial performance evaluation of schools, there is no way to highlight the characteristics and requirements of scientific research performance evaluation, which also makes the method of performance evaluation of university scientific research projects too simple and does not conform to the scientific research reality.

\section{Improve Countermeasures for Performance Evaluation of University Scientific Research Projects}

In order to improve and popularize the performance evaluation of university scientific research projects, it is necessary to solve the above problems, thus constructing a theoretical system, institutional system, evaluation system and method system for the performance evaluation of university scientific research projects.

First, improve the understanding of the status and role of the performance evaluation of university scientific research projects, and fully understand its importance in the management of scientific research projects in universities. The scientific research management department and the financial department of the university should fully realize that performance evaluation and management are 
the important content of efficient scientific research project management, and also the basic guarantee for ensuring the orderly, reasonable and efficient implementation of scientific research activities in colleges and universities, thus paying attention to the performance evaluation and management of university scientific research projects. The project leader should also realize that the research funds are not personal private funds, but government or enterprise funds for its scientific research activities, these funds should not only be used for the corresponding scientific research projects, but also must be used efficiently and reasonably, then reflect the value of scientific research funds, thus ensuring the benefit of scientific research activities and the results of scientific research results. At the same time, the acceptance and appraisal of various levels of projects and departments should also give enough attention to the importance of the performance evaluation of scientific research projects in universities, pay attention to the performance between expenditure and scientific research results in project acceptance and evaluation, thereby promoting the sound development and smooth progress of research activities in university scientific research projects.

Second, construct scientific and feasible system for performance evaluation of university scientific research projects, so that performance evaluation activities have rules to follow. First of all, it is necessary to establish complete institutional system, This institutional system must be based on the principles of economy, efficiency and effectiveness, carry out the overall planning of the system, put forward feasible evaluation system in accordance with the actual situation. Secondly, this system should define the working rules, working procedures, organization methods and result constraint force of the performance evaluation of university scientific research projects, and scientifically define the rights and obligations of the relevant behavior subjects. Finally, this system should establish the basic basis, basic indexes and basic system composition of performance evaluation of university scientific research projects, determine the basic scope, level and standards of performance evaluation, achieve performance evaluation can be carried out under a unified system, and ensures that different projects can apply the system according to their own characteristics.

Third, establish an effective index system for performance evaluation of university scientific research projects; ensure that the results of performance evaluation are fair, just, scientific and reasonable. After the system is determined, designing a scientific and reasonable index system and it will become the central link for the performance evaluation of university scientific research project. To this end, this index system should reflect the characteristics of scientific research work, integrate short-term index with long-term index. Generally speaking, the research of scientific research projects has certain age limit, but not all research can be completed within the project age limit, this requires that the performance evaluation index of scientific research should be formulated according to the approval age limit of the project, also consider the periodicity of scientific research itself, thus integrating two. That is to say, some projects can only achieve phased results when they reach the age limit, at this time, the performance evaluation index cannot be limited to only this age limit, but should also be formulated based on the progress of scientific research and the expected results of the future. At the same time, this index should combine its economic benefits and social effects when evaluating the effectiveness of scientific research, some research results of philosophy and social sciences may have no obvious economic benefits, but they have great social effects, therefore, we must not only look at economic benefits when formulating evaluation index, instead, combine the two to analyze it in detail. Finally, the evaluation index cannot only look at the number of results, but also the quality of the results. Some project results may be many in quantity, but their quality is not satisfactory, some projects may have few results, but their quality is very high, therefore, the evaluation index should pay more attention to the measurement of quality on the basis of ensuring the basic quantity.

Fourth, explore the evaluation methods of performance evaluation of university scientific research projects, and improve the accuracy of evaluation results. So far, there is no independent methodological system for the performance evaluation of university scientific research projects in China, under this condition, we can draw lessons from the financial performance evaluation method of university finance, integrate the characteristics of scientific research work, and innovate performance evaluation method of scientific research project. According to relevant experts' statistics, 
"the current theoretical circles have proposed cost-benefit analysis method, minimum cost method, comprehensive index method, factor analysis method, production function method, fuzzy math method, program comparison method, historical dynamic comparison method, target evaluation method, public evaluation method and so on." [1] 28-29 The method of performance evaluation of university scientific research projects should be based on the characteristics of scientific research work, integrate the above various methods, explore methods that meet the performance evaluation of scientific research, for example, integrate comprehensive index method and factor analysis method, cost-benefit analysis, refer cost-benefit analysis method and public judgment method, innovate performance evaluation method of university scientific research project, so that the performance evaluation of university scientific research projects can achieve higher accuracy, and truly reflects the process, characteristics, achievements and benefits of scientific research work in universities. Because the method of performance evaluation of university scientific research projects is still in the exploration process, form a targeted and effective method system as soon as possible, which will become one of the important contents for the improvement of the performance evaluation of university scientific research projects in the future.

\section{References}

[1]. Zhang Hue, College Financial Management and Performance Evaluation [J], Economic \& Trade Update, 2008(8).

[2]. Yang Jing Yuan. Discussion on Financial Performance Evaluation in University [J], China Management Informationization, 2011(4).

[3]. Li Hangman. Research on Financial Performance Evaluation of Colleges and Universities [J], Studies Of Finance and Accounting in Education, 2008 (6). 